cold. Here ve come to the $\mathrm{i}_{\mathrm{i}}$ uestion whether there is not a relation between the effect of cold upon a spray of especially exposed leaves upon a plant, and this determinate lesion in animal structure.

The cause of an untimely withering of a definite area, such as a branch of a single plant, may be very similar to that which has occurred here. It is, perhaps, most frequently seen as the result of watering in the sunshine of frosty weather. The plant-circulation is stimulated for the moment, to be checked to destruction in the night. The area affected will coincide with the least vigorous section of the plant, or, in the case of numbers, with the least vigorous specimens, equally exposed to the adverse influence. In much the same way, it is in accordance with elinical olservation, that the several tracts of grey matter, or definite brain-centres, may be unequally vigorous in a given individual. 'This may be due to hereditary conditions of con. figuration, or of intimate structure, as in cascs of limited infantile paralysis involving speech-centres or motor-centres; sometimes to incidental causes of circulation, as in abnormal distribution or varicose conditions, or the irregularities produced by abnormal use, and in epileptiform conditions of unstable equilibrium; and sometimes to disease, as in the completed results of scarlet fever and of specific disease.

The lesson to be derived from the casc now recorded is to sift to the bottom all obscure cascs, involving disturbance of function. Upon such information alone can be founded rational views of treatment, or, what is more important in such nerve-cases, of management, which should always be mainly directed to the restoration and conserva. tion of general health. These cases recover more or less completely, lepending on vigour of constitution. 'The progress is slow, and the process not easy to unilerstand. In some instances, particularly those of a gouty character, the lesion may be due to capillary $\mathrm{cm}$ bolism, the embolism being derived from gouty irritability of the lining membrane of the veins. In the case before us, it was more probably due to inflammatory action, eventually resulting in a dwindling or shrinkage of vessels. In that case, the circulation might in time becone renewed, hy anastomosis possibly, to the re. storation of functional activity. Warm clothing, the heat of summer, the assimilation of good food, and even the act of partaking of easily digested food (probably by withdrawal of circulation from the nervecentres to the acquirements of the digestive function), have marked effect on persons suffering from such lesions.

Becoming more vigorous in health during this spring, F. D. grallually lost the distressing vertiginous symptoms he had enclured since the autumn of 1884. Those experiencell during the day were the first to go ; and during this hot summer, they are all so far in abeyance. A recent rest and change in the country was of the greatest service to him. As is usual, certain of the precise painful spots where the herpetic eruption has destroyed tissue, remain persistently painful on being touched. There are times when the spots corresponding to nerve-terminations on the other side are painful. But, whatever be the process of recovery, substantial recovery has taken place in this case.

F. D. occasionally now has headache, which he call always refer to the left supratemporal region, as he places his hand to indicate the seat of hearlache. The original herpetic eruption was on the right shoulder.

The involvenent of the function of the auditory nerve, as in the vertiginous symptoms deseribed, and in the irritability caused by lond talking, noises in the street, and the sound of the bath-water in the ears, is difficult to account for in a lesion spending its force on a nervecentre so distunt as the origin of the circumflex nerve. It is interesting to note that, in the process of recovery, these auditory nervesymptoms were the first to go. The description of them reminds one of the temporary irritability caused by nervous headache. This nervous headache is possibly the most attenuated example of the epileptiform tendency. If so, it is probably due to hyperamia. The inflammatory lesion of nerve which produces herpes most probably leads to a temporarily persistent hyperemia affecting an area of central nerve-tissue wider than that on which the influm nation expencls the force which leads to organic: change.

In view that the insertion of the remarks on elementary pathology may seem fanciful, I should like, in conclusion, onco more to refer tho reader to Sir James Paget's suggestive paper, particularly to that part of it dealing with the repair of injuries ( $\mathrm{pp}$. 613-4 Op. cit.)

Loscevity.- - $A$ local paper states that, in the village of Cranborne near Salisbury, out of a population of 550 , there are two personis nged 89 years, two aged 87 , one 86 , two 84 , one 83 , and two 80 .

Dr. C. Lanoe, reader in Pathological Anutomy in the Cniversity of Copenhagen, lias been promoted to the rank of Professor.

\section{ON THE PERIODS OF ERUPTION OF THE PERMA-} NENT TEETH AS A TES'I OF AGE.

BY .IOHY LIVY, M.D. Bulton.

Unrul the passing of the Fantory anl W.nkshops Act, 1878, the certifying surgeons hal no other means of a w..rtaining the ago than those furnished hy the eruption of othin w: * of the perinanent teeth, and the gouernl physique of those presentiag themselves for examination. Since the A1:t enforces the prolurtion of a hirth-certificate, evidence of age from other sources is unneresaly. The subject, however, remains of practical valice, ani retains its interest from a biclogical as well as a forensi, point of view. The allu"atrure, the number, the "hararter, and clisposition of the teeth form nile of the inost valuable and important guiles in letermining the classitication of mammals. Their relations to the fool and habits of the animal, and the facility with which they can be examined, as well as their durability, render them alike interesting and instructive to the naturalist.

The object of this pajer, and the subjoined tables, have been simply to aseertain the periods of eruption of the permanent tecth. In onder to obtain reliable evidence of age, every rase was rejected where the birth-register could not be produced. Somnc authorities saly that the first molars appear at the cull of the fourth year; while others give it as late as the seventh year. In the case of children unclor ten years of age, who are not allowed to work in mills or workshiple, alventage was taken of the Eclueation Act, which requires the hirth-regixtor of every ehild on first groing to school. For the purpose of this inquiry, about 1,000 childhe' 11 were examined, 2,000 over 10 vears of ase, men at various mills and workshops in Bolton, and 2,000 under 10 years of age, attending varions schouls in the town. The class of children were those of the orlinaly working population of Bolton, a tawn containing over 100,000 inhahitants, and comprised the chilitren of mechanics, cotton-operatives, blcalhers, small shopkerpers, labourcra, ete. The annexed tables show a consillerable range in the periods of eruption.

As a single exception at the same time invalidates, and to some $\theta x$ tent suppofts, a general law, so, when the exceptions are numerous, as will be found to he the case here, a more or less high degree of probability is all that is attiinable. There is no law in hinolngy absolute. Nature is variable, and yet there is a certain uniformity. At the same time, it may be aftirmed that the eruption of the permanent teeth is the best physiological pro of of age that we pessews.

The typical number of teeth :ming placental mammalia is, aceord. ing to Owen, 44, to others 40 . Mammals only have a well marked division into four kinds; namely, incisors, canines, premulars, and molars. As is well known, the reduced human dental formils: numbers 32

The first and secont premulars in nan represent the third and fadrth premolars in those animals having four premolars.

In the chimpanzee and the orangs, the second nolar connes into position before the premolars. This, I have found, is a very fremuent occurrence in the human sulject, in both sexes, whilst the third of last molar is acquired liefore the canines.

When the typical number in diphyodont mammals is redurod, it is the first premolar that is absent, anel the third or last molar. The first molar is, therefore, the first of its series, whilst the second pre: molar is the last of its series, and the fourth of the ty piral dentition.

The premolars in man have never more than two fange, generally' only one. The first and second molars have two fangs in the lower jaw, sometimes convergent, and oceasionally divergent, placed anteriorly and posteriorly. In the upper jaw the molars diminish in sjoc from before backwards. They have three fange, and oceasionally fohr, twa extermal; the anterior is the longest. As a rule it $u$ ill be found tha external; the that the most vigorous and the nost we stated, almost axiomatically, the hildren of Irish purent: lave, as a rule, the hest devoloped tecth.

In boys between 4 and 5 years of age, the lower first molars cond tirst into place. In hoy's between 5 and 6 years of age, th.e first loter molars are acyuired tirst, in the ratio of fourtecn to one; at the same molars are acyluired the age the line The lower lateral inc 7 years of age, the lower first molars are acquirred boys between 6 and 7 years of age, the lower frist mo of thee to lower contral incisors are the first to rise into position, in comparison with the upper incisors are the first to rise into wilst the lower lateral incisorg invariajly firyt appear. In boys between 7 and 8 jears of age, the first lower molars come first into place, in the ratio of five to one. The lowe 
TaBLi A. - Boys.

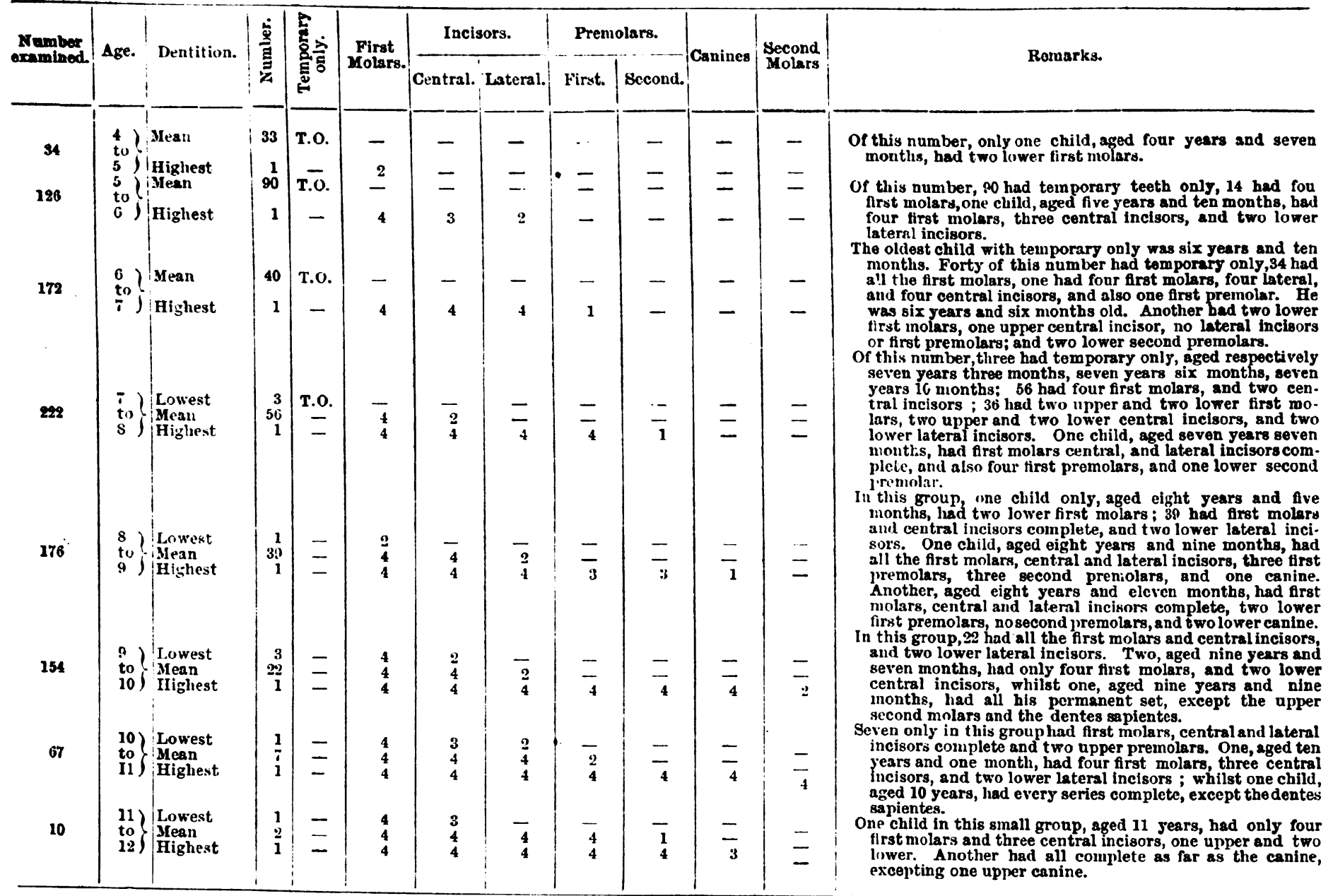

central incisors, as seventy-seven to one. The lower lateral incisors invariably appear first. The first premolars, representing the third in the typical number among the mammolia, come, as regards the upper and lower, into position in about equal proportions at this period of life.

In boys, during the ninth year, the first lower molars are invariably the first acquired. The lower central incisors show first, in the ratio of twenty to one. The lower lateral incisors, at this period of life, invariably show first. The upper first premolars show first as three to one. The upper second premolars, the fourth in the typical series, appear first in the ratio of two to one. At this age, the lower canines are invariably first acquired.

In boys between nine and ten years of age, the lower central and lower lateral incisors always cut the gum first. The upper first pre. molars appear first in the ratio of five to one. The upper second premolars rise into place in the ratio of seven to one. The lower canines and the lower molars invariably alpear first at this time of life.

In boys between ten and eleven years of age, the lower central and the lower lateral incisors invariably aplear first. The upper first premolars are first acquired in the ratio of three to one. The upper second premolars erupt first in the ratio of four to one. The lower canines invariably appear first. The second molars, upper and lower, appear first in equal proportions at this age.

In boys between eleven and twelve years of age, the second molars, upper and lower, are aequired in equal proportions in the small number examined, too small to attain anything like accuracy. The canines, as in previous ages, present in the lower jaw first.

In girls between the fourth and fifth year, the lower first nolars are the first to emerge into position, as in the case of boys of the same age.

In girls between five and six year's of age, the first lower molars are first acquired in the ratio of seven to one.

In girls between six and seven years of age, the first lower molars first come into position, in the ratio of eight to one. The lower central incisors precede the upper central in the ratio of thity to one, whilst the lower lateral incisors invariably appear first in this group.

In girls between seven and eight years, the first lower molars uniformly present first. The lower central incisors precede their antagonists in the ratio of sixty to one; the lower lateral incisors in the ratio of fifty to one. The first premolars appear first in this group in about equal proportions in each jaw. The same observation applies to the early eruption of the second premolars, and also to the canines at this carly period.

In girls in their ninth year, the lower central incisors invariably appear first, and the lower lateral, in the ratio of twenty to one. The upper first premolars appear first in the proportion of five to one, whilst the second upper premolars cut the gum first in the ratio of six to one. At this age, the lower canines are first acquired in the proportion of five to one.

During the tenth year, girls acquire the lower lateral incisors first, in the ratio of eleren to one. The upper first premolars come first into position, in the ratio of two to one. The second premolars show first in equal proportions in each jaw, whilst the lower canines invariably emerge from the gum the first in this group.

In girls between 10 and 11 years, the upper first premolars appear first in the ratio of two to one. The upper second premolars appear first in the ratio of five to one. The canines in this group invariably erupt the first in the lower jaw. The same remark applies to the second molar. In girls in their twelfth year, both the first and second upper premolars first pierce the gums, whilst it is the lower jaw that has precedence in the case of the canines and the second molars. It will be found that the number of rariations at each age steadily increases from five to ten or eleven in both sexes. It will also be observed that girls are slightly more advanced in their dentition (six ages out of eight). In two ages only, 6 and 7 years, are boys found alead of girls. 
TABLE B. - Girls.

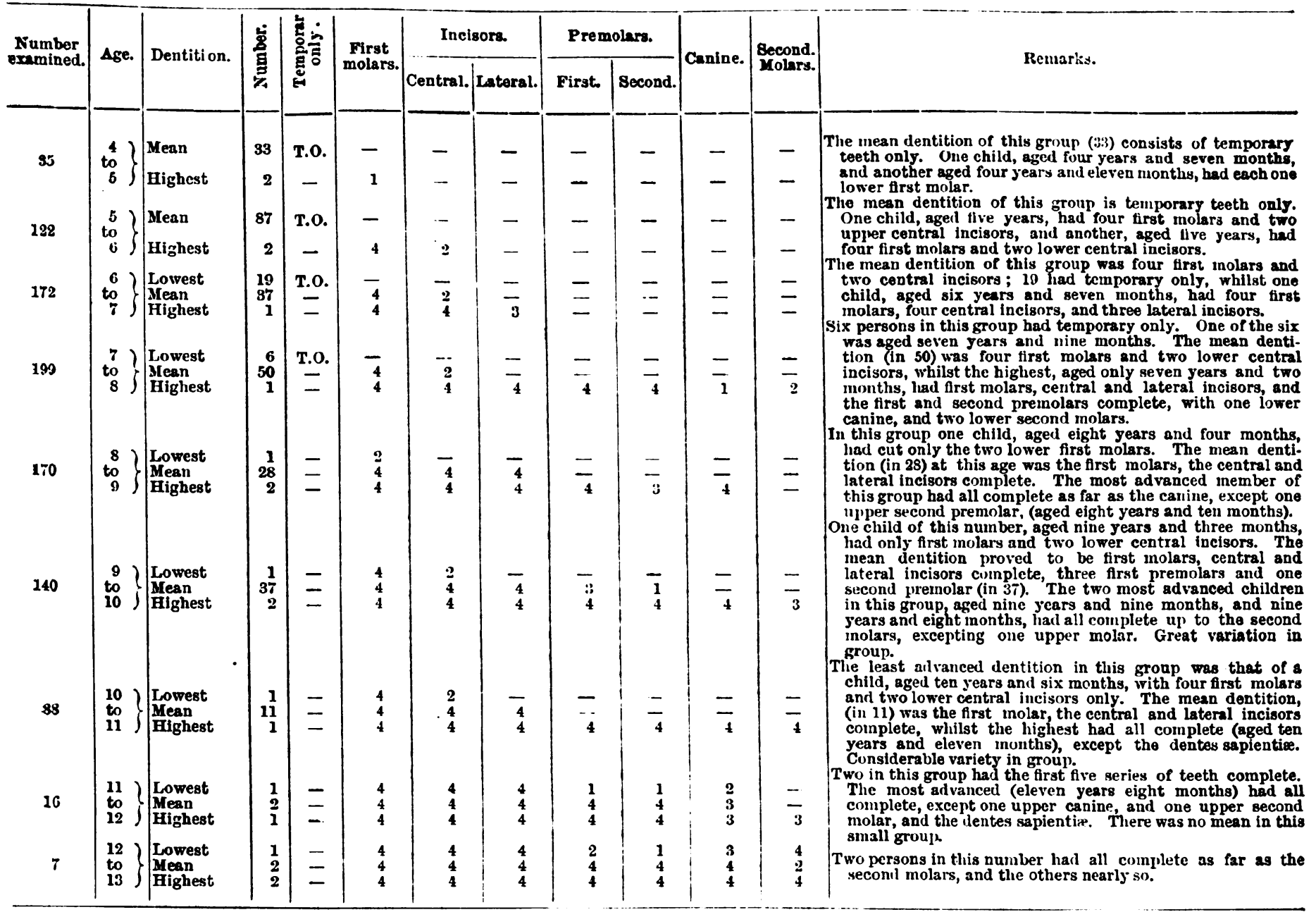

Table C. - Tabular Statement of Teeth (permancint), as a Test of Age in reference to Factory Children.

\begin{tabular}{|c|c|c|c|c|c|c|c|c|c|c|c|c|c|c|c|c|c|c|c|}
\hline \multirow{2}{*}{ Boys. } & \multicolumn{8}{|c|}{ Age. } & & \multirow{2}{*}{ Girls. } & \multicolumn{8}{|c|}{ Age. } & \multirow{2}{*}{ Total. } \\
\hline & 9 & 10 & 11 & 12 & 13 & 14 & 15 & 16 & fivat. & & 9 & 10 & 11 & 12 & 13 & 14 & 15 & 16 & \\
\hline Lateral Incisors . . & 2 & 42 & 9 & 4 & 1 & 1 & - & - & 59 & Lateral Inclsors & - & 24 & $s$ & 4 & - & - & - & - & 36 \\
\hline First Premolars . . & 1 & 76 & 12 & 1 & - & - & - & - & 80 & First Premolars & - & so & 13 & 2 & 1 & 1 & - & - & 73 \\
\hline Second Premolars. & - & 59 & 30 & 5 & - & 1 & - & - & 101 & Second Premolars. & - & 51 & 10 & 2 & 2 & - & - & - & 71 \\
\hline Canine . . . & - & 18 & 28 & $2 \pi$ & $\mathrm{s}$ & - & - & - & 79 & Canine . . . & - & 30 & 34 & 12 & j & - & 1 & - & 82 \\
\hline \multirow[t]{2}{*}{ Second Molars . . . } & \multirow[t]{2}{*}{-} & \multirow[t]{2}{*}{5} & \multirow[t]{2}{*}{42} & \multirow[t]{2}{*}{$0 \pi$} & \multirow[t]{2}{*}{275} & \multirow[t]{2}{*}{184} & \multirow[t]{2}{*}{78} & 12 & 663 & \multirow[t]{2}{*}{ Second Molars . . } & \multirow[t]{2}{*}{-} & \multirow[t]{2}{*}{ j } & \multirow[t]{2}{*}{44} & \multirow[t]{2}{*}{ so } & \multirow[t]{2}{*}{$2 s s$} & \multirow[t]{2}{*}{249} & \multirow[t]{2}{*}{ e0 } & 14 & 746 \\
\hline & & & & & & & & Total & 992 & & & & & & & & & Total & 1008 \\
\hline
\end{tabular}

N.B. -The numbers belor each age refer to the appearances of one or more of the series of teeth stated. For example-0f $j 9$ boys with the lateral incisors as their eldest teeth, two were nine years of age, 42 were ten, nine were eleven, \&c.

During the course of this inquiry, I could not help observing that caries is extremely common ; indeed, it is quite the exception to find a perfect set of teeth, more especially among children over 10 years of age. This is largely due to want of care in the management of the teoth.

I have no doubt that the excessive use of sugar and tea is one of the principal causes of dental caries. Favoured by the temperature of the mouth, saccharine fermentation will terminate in the formation of butyric, lactic, and acetic acids, all of which exert a solvent action on the enamel. When this latter has given way, the dentine becomes an easy prey to the same process. The tannic acid found in tea exerts a similar chemical effect on the teeth. Small pieces of meat lying between the teeth will likewise contribute to the production of caries According to some recent experiments, bacteria of a special form are an essential element in the production of dental caries; one more illustration, if it were not unnecessary, to prove the pervading influence of micro-organisms in the ever growing class of enthetic diseases. 
TABLE E

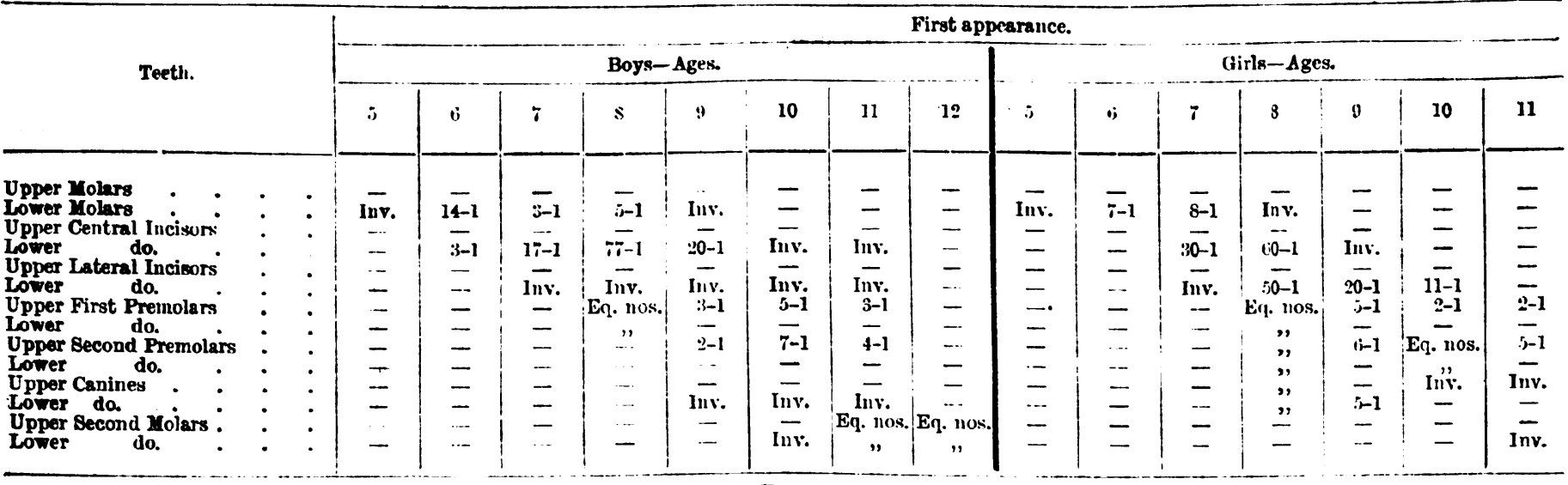

Inv. Invariable. Eq. nos. Equal numbers.

N.B.-This tab?e has been made to show the priority of the teeth of the npper and lower jaw in each series. Ex.-In boys of five years the lower molars invarially appear first. In boys of six years the sime teeth appear first in the ratio of fourteen to one.

TABLE F.- Tiemiber of Vuriations in each Age.

\begin{tabular}{|c|c|c|c|c|c|}
\hline \multicolumn{3}{|c|}{ Boys. } & \multicolumn{3}{|c|}{ Girls. } \\
\hline Number. & Year. & Variation. & Number. & Year. & Variation. \\
\hline 34 & 5 th & 1 & 35 & ith & $::$ \\
\hline 126 & cth & $\mathrm{s}$ & 122 & ith & $i$ \\
\hline 172 & ith & 21 & 172 & ith & 19 \\
\hline 222 & Sth & 28 & 199 & sth & 34 \\
\hline 176 & $9+\mathrm{th}$ & 39 & 170 & sth & 41 \\
\hline 154 & 10th & 44 & 140 & 10 th & j4 \\
\hline 67 & 11th & 33 & 88 & 11 th & 33 \\
\hline 10 & 12th & 9 & $1 t i$ & 12 th & $1: 3$ \\
\hline
\end{tabular}

\section{CASE OF DETACHMENT OF THE RETINA, WITH CHOLESTERINE IN THE SCBRETINAL FLUID.}

BY L. WERNER, M.B., B.CH.,

House-Surgeon to the National Eye and Ear Infirmary, Dubliu.

A. E., a healthy looking lad, aged 8, was admitted to the Infirmary, under the care of Mr. Swanzy, on the 8th of February last, complain. ing of blindness of the left eyc. His family-history was good, with the exception of one brother, who is idiotic ; but none of the family have ever suffered from eye-disease. The boy himself had always enjoyed good health up to March, 1884, when he was confined to his bed for three or four days with a bad headache. In July following, while climbing over a ditch, he received a blow from a broken branch on the left eye. The "white" of tine eye, it would appear, was torn ou the nasal side, and there was a little bleeding. The sight was affected immediately after the injury, but, according to the mother's statement, it recovered in a few days. From this time, nothing wrong was noticed until Christmas, when the boy accidentally discovered that he could not see if the right eye were covered. In January last, Dr. Warnock of Trillick (to whom I am indebted for many points in the history of the case) treated him for a severe pain in the left eyebrow and temple. The eye was neither congested nor painful at the time, but the pupil was somewhat dilated.

The following was the condition on admission. Perception of light was completely wanting; the anterior chamber was shallow; the pupil, which corresponded in size with that of the other eye, did not react to light, although contracting consensually and on convergence By good daylight, a shining greyish reflection was visible in the interior of the eye. There was no perceptible difference in the intraocular tension of the two eyes; but in each it was, if anything. slightly below the average normal tension. Viewed by focal illumination, the grey appearance of the pupil wiss seen to be due to an infinite number of minute sparkling crystals, apparently held in suspen. sion by some substance which seemed to float in the vitreous humour when the eye was moved. The separate particles appeared, at first, to have no motion, except that which was imparted to them by the mass in which they were imbedded; but on closer observation, when the eye, after having been movel in various directions, came to rest, some of the crystals could be seen falling slowly towards the inferior part of the globe, while others remained suspended opposite the pupil. When the pupil had been fully lilatid by atropine, it was found that the retina was very extensively deta hed, aid that the crystals were situated, not in the vitreous humour, but between the choroid and the retina (that is, in the subretinal fluid), for the latter, although still transparent, could be distinctly seen in front of the sparkling mass. Several of the retinal resscls had a curved arrangement, with their concavity directed forwards, owing to the close apposition of the retina to the posterior surface of the lens. The temporal portion was completely letached, and stretched across, behind the lens, to the inner side of the eye, where it dipped back towards the fundus, the edge of the fold forming a bright line directed from above, downwarls and inwards (as seen on a large scale in Fig. 1).

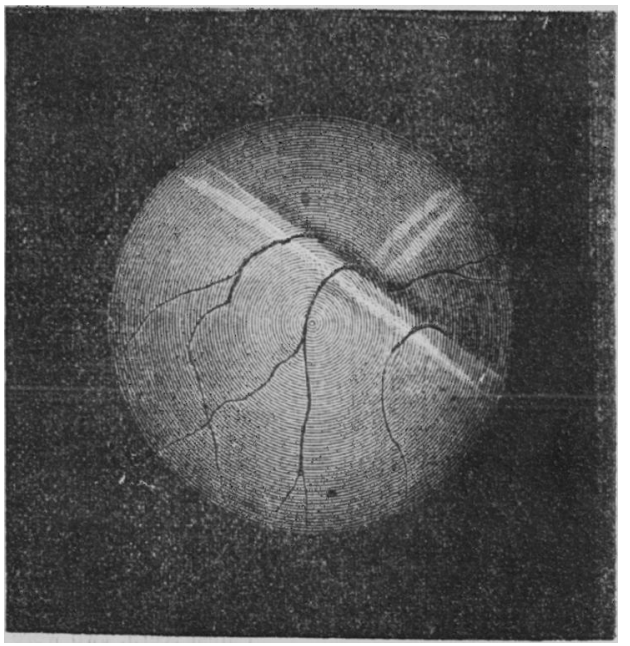

Fig. 1. Showing the retina as seen by focal illumination through the dilated pupil, the eye being rotated upwards and in wards.

The nasal side of the retina was also detached, and similar crystale shone through it, and towards the upper part it presented two narrow folds running antero-posteriorly.

Some of the above details were hidden behind the inner side of the iris ; and hence, in order to see them, the eye required to be ro. tated well inwards, and the light thrown in very obliquely. Tho fundus was, of course, invisible with the ophthalmoscope, and the 